\title{
CMOS-Integrated Si/SiGe Quantum-Well Infrared Microbolometer Focal Plane Arrays Manufactured With Very Large-Scale Heterogeneous 3-D Integration
}

\author{
Fredrik Forsberg, Adriana Lapadatu, Gjermund Kittilsland, Stian Martinsen, Niclas Roxhed, Andreas C. Fischer, \\ Göran Stemme, Fellow, IEEE, Björn Samel, Per Ericsson, Nils Høivik, Thor Bakke, Member, IEEE, Martin Bring, \\ Terje Kvisterøy, Audun Rør, and Frank Niklaus, Senior Member, IEEE
}

\begin{abstract}
We demonstrate infrared focal plane arrays utilizing monocrystalline silicon/silicon-germanium ( $\mathrm{Si} / \mathrm{SiGe}$ ) quantumwell microbolometers that are heterogeneously integrated on top of CMOS-based electronic read-out integrated circuit substrates. The microbolometers are designed to detect light in the long wavelength infrared (LWIR) range from 8 to $14 \mu \mathrm{m}$ and are arranged in focal plane arrays consisting of $384 \times 288$ microbolometer pixels with a pixel pitch of $25 \mu \mathrm{m} \times 25 \mu \mathrm{m}$. Focal plane arrays with two different microbolometer designs have been implemented. The first is a conventional single-layer microbolometer design and the second is an umbrella design in which the microbolometer legs are placed underneath the microbolometer membrane to achieve an improved pixel fill-factor. The infrared focal plane arrays are vacuum packaged using a CMOS compatible wafer bonding and sealing process. The demonstrated heterogeneous 3-D integration and packaging processes are implemented at wafer-level and enable independent optimization of the CMOS-based integrated circuits and the microbolometer materials. All manufacturing is done using standard semiconductor and MEMS processes, thus offering a generic approach for integrating CMOS-electronics with complex miniaturized transducer elements.
\end{abstract}

Index Terms-Long-wavelength infrared imaging, LWIR, thermal imaging, uncooled microbolometer, Si/SiGe quantum-wells, wafer-level vacuum packaging, very large-scale heterogeneous 3-D integration, MEMS.

Manuscript received April 24, 2014; revised August 2, 2014; accepted September 8, 2014. Date of publication September 16, 2014; date of current version September 30, 2014. This work was supported by the European Commission through the EU-FP7-ICU project, EU-FP7- e-Brains project, the ESiP project by ENIAC JU, Norwegian Research Council, and the ERC Starting Grant M\&M's (No.277879).

F. Forsberg, N. Roxhed, A. C. Fischer, G. Stemme, and F. Niklaus are with the Department of Micro and Nanosystems, KTH Royal Institute of Technology, 10044 Stockholm, Sweden (e-mail: fredrik.forsberg@ee.kth.se; niclas.roxhed@ee.kth.se; andreas.fischer@ee.kth.se; goran.stemme@ee.kth.se; frank.niklaus@ee.kth.se).

A. Lapadatu, G. Kittilsland, S. Martinsen, M. Bring, T. Kvisterøy, and A. Rør are with the Sensonor AS, 3194 Horten, Norway (e-mail: adriana. lapadatu@sensonor.no; gjermund.kittilsland@sensonor.no; stian.martinsen@ sensonor.no; martin.bring@gmx.com; terje.kvisteroey@sensonor.no; audun. roer@sensonor.no).

B. Samel and P. Ericsson are with the ACREO Swedish ICT, SE-164 25 Kista, Sweden (e-mail: bjorn.samel@acreo.se; per.ericsson@acreo.se).

N. Høivik is with the Department of Micro and Nano Systems, Vestfold University College, N-3103 Tønsberg, Norway (e-mail: Nils.Hoivik@ hbv.no).

T. Bakke is with the Department of Microsystems and Nanotechnology, SINTEF ICT, Microsystems and Nanotechnology, 0314 Oslo, Norway (e-mail: Thor.Bakke@sintef.no).

Color versions of one or more of the figures in this paper are available online at http://ieeexplore.ieee.org.

Digital Object Identifier 10.1109/JSTQE.2014.2358198

\section{INTRODUCTION}

$\mathbf{L}$ ONG-wavelength infrared (LWIR) imaging, also called thermal imaging, is quickly spreading beyond its initial defense-related applications into areas as diverse as thermography, medical imaging, industrial process control, person detection, person counting, automotive safety and even consumer products such as mobile phones [1]-[5]. In thermal imaging, the electromagnetic blackbody radiation that is emitted by every object with a non-zero temperature is detected. The blackbody radiation of objects at ambient temperature has a maximum intensity at a wavelength of about $10 \mu \mathrm{m}$, which corresponds with the atmospheric transmission window between 8 and $14 \mu \mathrm{m}$ for infrared (IR) radiation [6]. An important advantage of thermal imaging is that the resulting images are independent of ambient light conditions and thus, enables imaging in complete darkness. Thermal images are often easier to interpret by automatic vision algorithms and provide information that is complementing to images taken in the visible wavelengths range [3], [7]. Furthermore, thermal imaging allows for temperature mapping and non-contact temperature measurements [8]. In a typical thermal imaging system, infrared radiation with wavelengths from 8 to $14 \mu \mathrm{m}$ is captured by an IR lens system and focused onto a sensor focal plane array (FPA) that detects the radiation. Commercially available thermal imaging systems typically utilize uncooled resistive microbolometer sensor technologies for radiation detection [9]. In a microbolometer, the incoming thermal radiation is absorbed in a suspended and thermally isolated membrane. The absorption increases the temperature of the membrane. The temperature change of the membrane is detected by measuring the resulting change of the electrical resistance of the microbolometer thermistor material that is part of the membrane. The resistance value of each microbolometer pixel in a focal plane array correlates with the incoming radiation energy and registers the thermal image information. Microbolometers that deliver high signal-to-noise ratios require very good thermal insulation of the membrane containing the thermistor material, large resistance changes with temperature changes of the thermistor material, high absorption of the IR radiation in the microbolometer membrane and low electronic noise from the thermistor material [10]-[12]. The microbolometer membrane is typically suspended on long legs 
with a small cross-sectional area to achieve a good thermal insulation. In addition, microbolometer arrays are encapsulated inside a vacuum atmosphere with a gas pressure on the order of $10^{-2}$ to $10^{-3}$ mbar [12], [13]. The microbolometer thermistor material is likewise optimized for a high temperature coefficient of resistance (TCR) while minimizing the electronic noise from the material. The vast majority of commercially available uncooled infrared focal plane arrays are based on microbolometers containing vanadium oxide $\left(\mathrm{VO}_{\mathrm{x}}\right)$ or amorphous silicon $(\alpha-\mathrm{Si})$ thermistors, both featuring TCRs on the order of $2-3 \% / \mathrm{K}$ [14]-[19]. In both cases, the microbolometer materials are deposited and patterned on top of pre-fabricated CMOS wafers containing the read-out integrated circuits (ROIC) for the detector signal read-out. This manufacturing approach is typically referred to as monolithic integration and is temperature limited to below $400-450{ }^{\circ} \mathrm{C}$ for the microbolometer material deposition to avoid damaging the CMOS electronic circuits [20], [21]. Therefore, the optimization of thermistor materials used in monolithic integration is difficult with repercussions on quality, uniformity and yield. Heterogeneous 3-D integration based on wafer bonding has the potential to alleviate these fabrication related issues of state-of-the-art microbolometer focal plane arrays [22]-[24]. In heterogeneous 3-D integration, the microbolometer thermistor material is fabricated on a handlewafer and subsequently transferred to a prefabricated CMOSbased read-out integrated circuit wafer using wafer bonding, wafer thinning and subsequent micromachining. This approach allows for a higher temperature budget and thus a wider selection of possible high-performance detector materials as compared with monolithic integration approaches. Very large-scale heterogeneous 3-D integration processes for combining CMOSelectronics and micro-electromechanical systems (MEMS) have been demonstrated for IC-integrated micro-mirror arrays [25][29], IC-integrated accelerometers [30] and for gyroscopes [28], [31]. Heterogeneous 3-D integration for IR microbolometer focal plane arrays has also been proposed [4], [22]-[24], [32][35]. In this paper, we demonstrate infrared microbolometer focal plane arrays utilizing mono-crystalline silicon/silicongermanium $(\mathrm{Si} / \mathrm{SiGe})$ quantum-well thermistors that are heterogeneously integrated on top of pre-fabricated CMOS-based read-out integrated circuit wafers. The microbolometer focal plane arrays consist of $384 \times 288$ pixels with a pixel pitch of $25 \mu \mathrm{m} \times 25 \mu \mathrm{m}$. Focal plane arrays with two different microbolometer designs have been implemented and evaluated. The first microbolometer design is a traditional membrane design in which the microbolometer legs are placed along the edges of the microbolometer membrane [35]. The second microbolometer design is an umbrella-type design in which the legs are placed underneath the microbolometer membrane to increase the pixel fill factor [22], [36], [37]. A wafer-level solidliquid interdiffusion (SLID) bonding process with copper $(\mathrm{Cu})$ and tin (Sn) [13], [38], [39] is used to cap and vacuum package the infrared microbolometer focal plane arrays. The cap wafer contains anti-reflective coatings to maximize the transmission of the LWIR band through the package window. A non-evaporative getter material is implemented inside the package to further enhance the vacuum level. The packaged infrared microbolometer

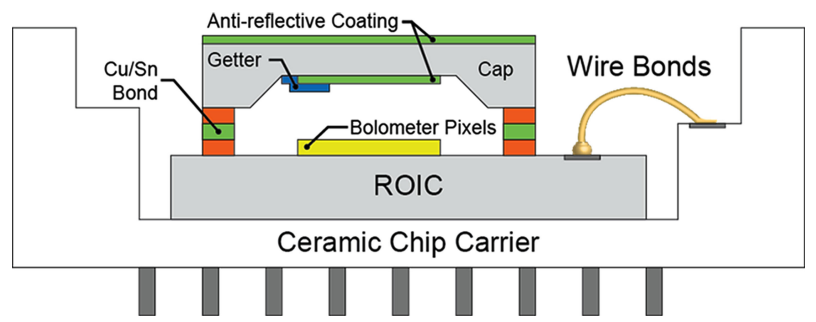

Fig. 1. Schematic cross-section of the packaged microbolometer focal plane array module.

focal plane arrays are implemented in a camera module together with LWIR optics to demonstrate the capture of LWIR video images.

\section{INFRARED MicRobolometer FocAl PlANE ARRAY DESIGN AND IMPLEMENTATION}

Fig. 1 shows a cross-sectional drawing of the packaged infrared microbolometer focal plane array module. It includes the heterogeneously integrated $\mathrm{Si} / \mathrm{SiGe}$ quantum well microbolometers on top of a CMOS-based readout integrated circuit substrate and the 0 -level vacuum package based on a silicon lid that is bonded to the CMOS substrate which is placed in a ceramic chip carrier. The design and implementations of the packaged microbolometer focal plane array is described in the subsequent sections that provide details on the readout integrated circuit, the microbolometer design and integration, and the wafer-level vacuum package.

\section{A. Read-Out Integrated Circuit}

The microbolometer read-out integrated circuit in this paper is implemented in a standard commercial $0.18 \mu \mathrm{m}$ CMOS foundry process. Fig. 2 shows a high-level block diagram of the readout integrated circuit electronics. The focal plane array circuit contains an area for an array of $384 \times 288$ microbolometer pixels with a pixel pitch of $25 \mu \mathrm{m} \times 25 \mu \mathrm{m}$ along with on-chip analog to digital conversion, compensation and communication circuitry.

The analog signal chain in the read-out integrated circuit consists of microbolometer biasing, chopper amplifier, integrator, sample-and-hold, multiplexing and analog-to-digital conversion. The microbolometer pixels are read out sequentially for each row and in parallel for all columns. Therefore, each individual microbolometer in a row is biased together with a blind reference microbolometer pixel that is located at the end of every row and not exposed to incoming infrared radiation. There are two communication interfaces on the focal plane array. The first interface is a serial peripheral interface (SPI) that is used for device configuration together with test and debugging. The second interface is a low-voltage differential signaling (LVDS) interface that is used to transfer low-level calibration data out of the focal plane array. The CMOS wafers containing the circuits are provided by the foundry and the infrared microbolometers are subsequently integrated on top of the CMOS wafer using the heterogeneous 3-D integration processes described in Section II-B. 


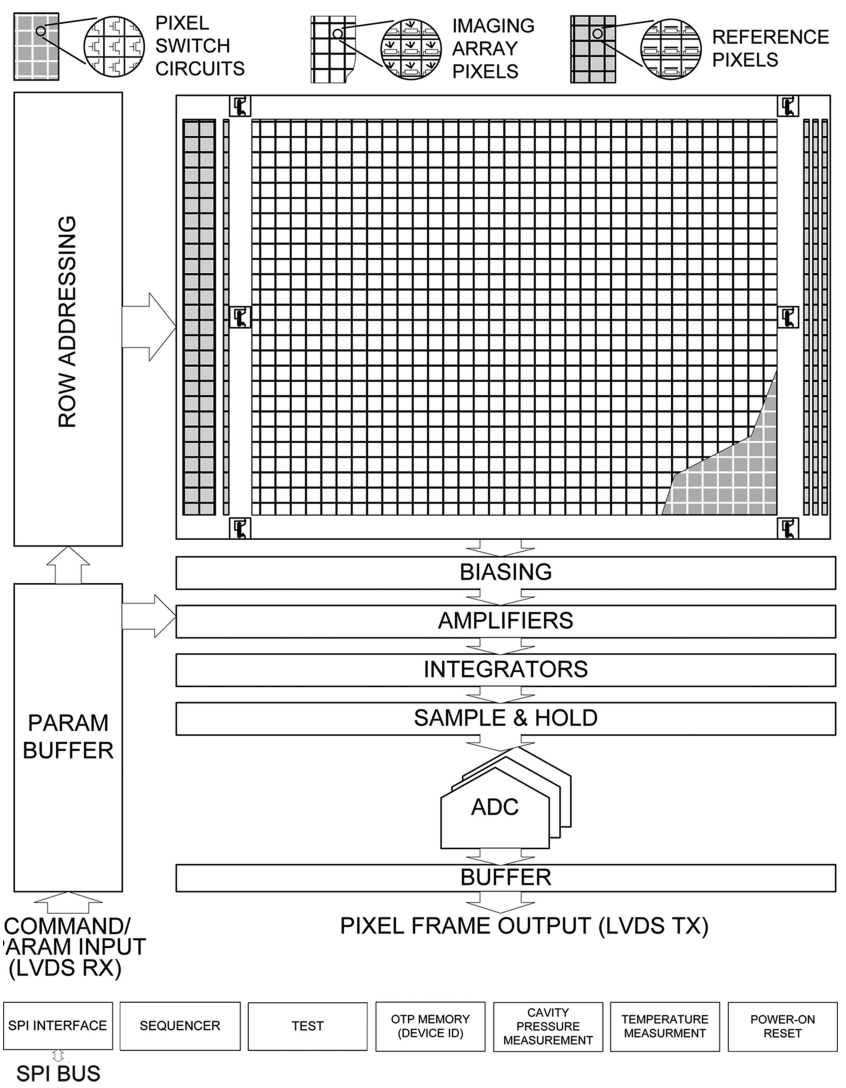

Fig. 2. High-level block-diagram of the CMOS-based focal plane array readout integrated circuit.

\section{B. Microbolometer Design and Integration}

The microbolometers in this work utilize a Si/SiGe quantumwell thermistor material [40], [41]. Mono-crystalline Si/SiGe quantum-well thermistors feature comparably high TCRs and low electronic noise as reported in previous works [23], [35], [41]. This type of thermistor material consists of thin SiGe quantum well layers that are sandwiched between layers of $\mathrm{Si}$, which allows tailoring the TCRs to between $-2.5 \% / \mathrm{K}$ and $-4 \% / \mathrm{K}$ along with good $1 / \mathrm{f}$ noise properties [41]. The TCR of the quantum-well thermistor material results from thermal excitation of charge carriers from quantum-well-confined lowenergy states where the carriers are comparatively immobile, to excited states where they are highly mobile. The TCR increases with an increasing difference between the lowest energy of the conducting charge carriers and the confined state. For the quantum-wells used in the bolometer thermistor, the largest TCR is obtained with the largest possible confinement energy barrier. Hence, increasing the Ge content and/or the well width in $\mathrm{SiGe/Si} \mathrm{quantum-wells} \mathrm{increases} \mathrm{the} \mathrm{TCR} \mathrm{value.} \mathrm{More} \mathrm{details}$ about the thermistor material are provided in [42]. Fig. 3 shows a schematic cross-section of the thermistor material structure. As indicated in Fig. 4, the microbolometer current path through the thermistor material is vertical to the thermistor surface through the $\mathrm{Si} / \mathrm{SiGe}$ quantum-well layers. To achieve a high TCR, low doped, wide and Ge-rich quantum well layers are used. The SiGe quantum-well layers typically contain $30-35 \%$ Ge and

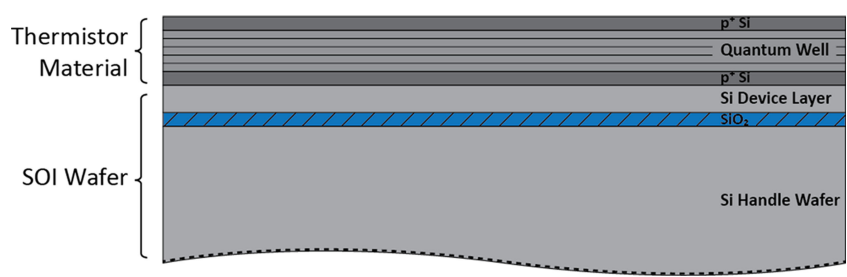

Fig. 3. Schematic cross-section of the thermistor material handle wafer consisting of a SOI wafer and the epitaxially grown $\mathrm{Si} / \mathrm{SiGe}$ quantum-well thermistor material.

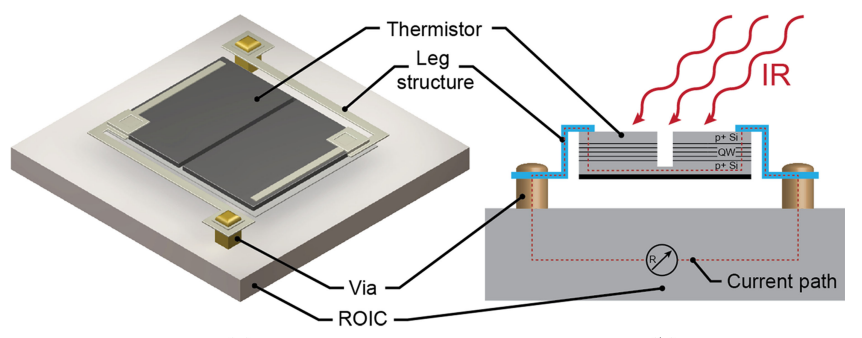

(a)

(b)

Fig. 4. (a) Reduced 3-D image of the microbolometer pixel, including the microbolometer legs and the via posts that connect the microbolometer legs and the read-out integrated circuit. (b) Schematic cross-section of the single-layer microbolometer design with current path through the $\mathrm{Si} / \mathrm{SiGe}$ quantum-well thermistor. The trench separates the highly doped Si between the upper contacts.

are $8-10 \mathrm{~nm}$ thick. The thermistor material used in this work has a measured TCR of $-2.9 \% / \mathrm{K}$ [23]. The mono-crystalline $\mathrm{Si} / \mathrm{SiGe}$ quantum-well thermistor material cannot be directly deposited on top of the CMOS wafer since the epitaxial deposition process requires a mono-crystalline silicon seed layer and the temperatures that are reached during deposition exceed the temperature allowed for the CMOS electronic circuits. Therefore, the $\mathrm{Si} / \mathrm{SiGe}$ quantum-well thermistor material is deposited on a SOI wafer, in the following called thermistor material handle wafer. The deposited thermistor material is subsequently transferred to the CMOS wafer using wafer-level heterogeneous 3-D integration. The design and implementation of the focal plane arrays with two different microbolometer designs, i.e., a conventional single-layer design and a two-layer umbrella design, respectively, are described in Sections II-B1 and II-B2. While the umbrella microbolometer design consists of a slightly more complex structure, its key advantage is that the bolometer legs are placed underneath the microbolometer membrane and not beside the membrane as for the conventional single-layer microbolometer design. Thus, a higher pixel fill-factor of $72 \%$ (excluding the thermistor contact areas) is obtained for the umbrella design, while standard, low-resolution projection lithography can be used for the microbolometer fabrication. In principle, the fill-factor of the umbrella design can be further improved to well above $80 \%$ if high-resolution stepper-lithography is used. In contrast, the single-layer microbolometer design features a pixel fill-factor of 59\% (excluding the thermistor contact areas) and requires high-resolution stepper-lithography for the fabrication. Thus, the umbrella microbolometer design can obtain increased infrared light absorption, while featuring less stringent 


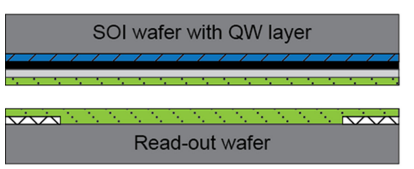

(a)

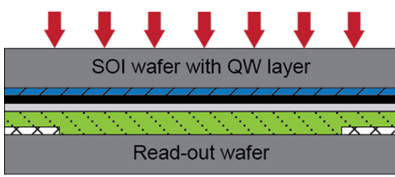

(b)

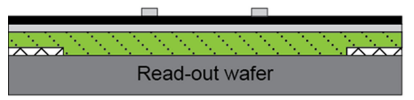

(c)

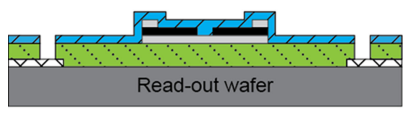

(d)

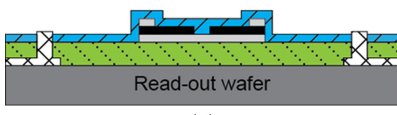

(e)

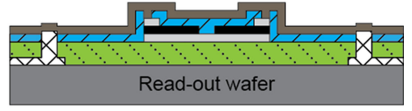

(f)

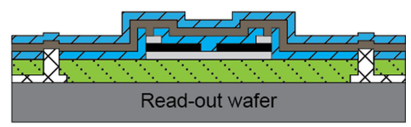

(g)

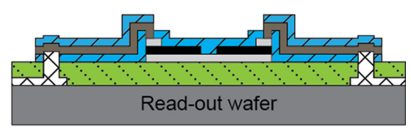

(h)

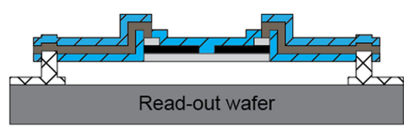

(i)

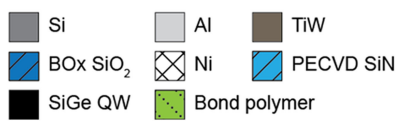

SiGe QW $\because$ Bond polymer
Fig. 5. Schematic process for heterogeneous 3-D integration of the single layer microbolometer design on top of a pre-fabricated CMOS-based read-out integrated circuit wafer.

demands on the lithographical resolution during microbolometer fabrication.

1) Conventional Single-Layer Microbolometer Design: Fig. 4(a) and (b) show a rendered 3-D image and a crosssectional image of the conventional microbolometer design, respectively. In this design, the microbolometer legs consist of a sandwich structure of silicon nitride ( $\mathrm{SiN}$ ), titanium tungsten (TiW) and SiN to both stress compensate the leg and encapsulate the thin TiW film that provides the electrical contact between the nickel (Ni) vias and the thermistor material. The legs connect to $\mathrm{Al}$ contacts on the top layer of the $\mathrm{Si} / \mathrm{SiGe}$ thermistor. An etched trench disconnects the two top contacts on the $\mathrm{Si} / \mathrm{SiGe}$ thermistor material from each other through the uppermost highly doped Si contact layer. This configuration is used to guide the measurement current vertically through the horizontally arranged $\mathrm{Si} / \mathrm{SiGe}$ quantum wells of the microbolometer membrane. The infrared absorption of the microbolometer is optimized by designing it as an optical $\lambda / 4$-cavity where the incoming IR radiation is reflected from the backside metal mirror and absorbed by the microbolometer membrane [43]. The optical cavity consists of a bottom Al mirror, the epitaxially grown $\mathrm{Si} / \mathrm{SiGe}$, PECVD-deposited $\mathrm{SiO}_{2}$ and $\mathrm{SiN}$ passivation layers and a thin antireflective top $\mathrm{MoSi}_{2}$ coating (not indicated in Fig. 4). The optical design of the $\lambda / 4$-cavity was simulated and optimized to absorb $>80 \%$ of the optical power of the targeted wavelengths from 8 to $14 \mu \mathrm{m}$. The cross-section of the optical cavity is shown in Fig. 4(b) together with the electrical current path. Plated Ni vias connect the microbolometer legs to interconnect lines on the CMOS read-out integrated circuit substrate.
Fig. 5 details key steps in the heterogeneous 3-D integration of the single-layer microbolometers on top of the read-out integrated circuit wafer. The process starts with the pre-fabricated CMOS-based read-out integrated circuit wafer and the $\mathrm{Si} / \mathrm{SiGe}$ thermistor that is epitaxially grown on the SOI-based thermistor material handle wafer. A $20 \mathrm{~nm}$ thick PECVD $\mathrm{SiO}_{2}$ layer is deposited on the thermistor material handle wafer and a $50 \mathrm{~nm}$ thick layer of $\mathrm{Al}(1 \% \mathrm{Si})$ is sputtered on top of the deposited $\mathrm{SiO}_{2}$ layer to define the microbolometer backside mirror as shown in Fig. 5(a). A Ni seed layer is deposited on the CMOS wafer at the contact points to which the Ni via-posts are connected to the read-out integrated circuit. At this point, the height of the surface topography of the CMOS wafer is approximately $1 \mu \mathrm{m}$. The thermistor material handle wafer and the CMOS wafer are each spin-coated with a $1.5 \mu \mathrm{m}$ thick polymer layer (mr-I 9150XP, Microresist Technology $\mathrm{GmbH}$ ) that is soft-baked at $100{ }^{\circ} \mathrm{C}$ for $3 \mathrm{~min}$. The two wafers are adhesively bonded as indicated in Fig. 5(b) using a bond force of $12 \mathrm{kN}$ on the $100 \mathrm{~mm}$ diameter wafer stack together with a bonding temperature of $200{ }^{\circ} \mathrm{C}$ [44], [45]. Wafer-to-wafer alignment is not required for the wafer bonding step. The Si substrate of the SOI-based thermistor material handle wafer is removed using an $\mathrm{SF}_{6}$-based deep reactive ion etch (DRIE) process, stopping on the $\mathrm{SiO}_{2}$ layer (BOX). The $\mathrm{SiO}_{2}$ layer is then removed in buffered $\mathrm{HF}$ as indicated in Fig. 5(b). A $30 \mathrm{~nm}$ thick layer of $\mathrm{Al}(1 \% \mathrm{Si})$ is sputter-deposited and defined into contact pads on top of the transferred $\mathrm{Si} / \mathrm{SiGe}$ quantum well thermistor layer as shown in Fig. 5(c). The $\mathrm{Si} / \mathrm{SiGe}$ quantum well layer is then covered with a $100 \mathrm{~nm}$ thick layer of PECVD $\mathrm{SiO}_{2}$ that is deposited at $100{ }^{\circ} \mathrm{C}$ to be used as a hard mask, followed by masking and etching to define the thermistor structures in the microbolometer arrays. The results are $\mathrm{Si} / \mathrm{SiGe}$ quantum well mesas with Al top contacts placed on top of the bonding polymer. The mesas are covered with another thin (less than $50 \mathrm{~nm}$ ) layer of PECVD $\mathrm{SiO}_{2}$ to seal-off the exposed bonding polymer. This is done because the elevated temperatures in an oxygen-containing atmosphere would otherwise degrade the bonding polymer. The first of two forming gas anneals is performed with $\mathrm{Ar} / \mathrm{H}_{2}$ for $30 \mathrm{~min}$ at $300{ }^{\circ} \mathrm{C}$. The wafer is then blanket-dry-etched to remove the $\mathrm{SiO}_{2}$ layer from the surface. This is followed by the deposition of a $150 \mathrm{~nm}$ thick layer of PECVD SiN to cover both the bonding polymer and the $\mathrm{Si} / \mathrm{SiGe}$ quantum well mesas that form the microbolometer thermistor membranes. Via-holes with a diameter of $3 \mu \mathrm{m}$ are defined and etched through the SiN and the bonding polymer down to the Ni seed layer on the CMOS wafer as shown in Fig. 5(d). Ni is plated to fill the via-holes using electroless plating as indicated in Fig. 5(e). A $50 \mathrm{~nm}$ thick layer of TiW is deposited to electrically connect the thermistors with the plated Ni vias as shown in Fig. 5(f). The TiW metal is patterned to pre-define parts of the microbolometer legs. Another $200 \mathrm{~nm}$ thick layer of PECVD SiN is deposited to obtain a triple stack leg structure of $\mathrm{SiN}$, TiW and $\mathrm{SiN}$ that enables stress-compensated non-bending microbolometer legs. This is followed by a patterning step that defines the microbolometer legs and the microbolometer membranes as shown in Fig. 5(h). The microbolometer structures that are integrated on top of the CMOS wafer are free-etched by removing the bonding polymer 


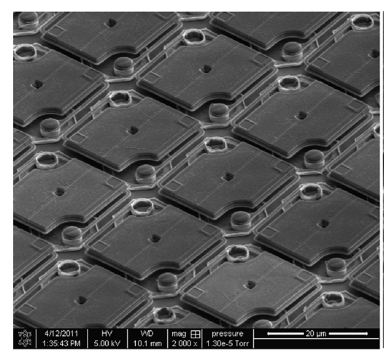

(a)

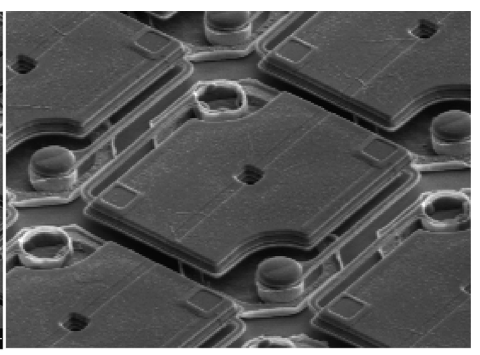

(b)
Fig. 6. SEM images of the conventional single-layer microbolometer design integrated on top of a CMOS read-out integrated circuit wafer.

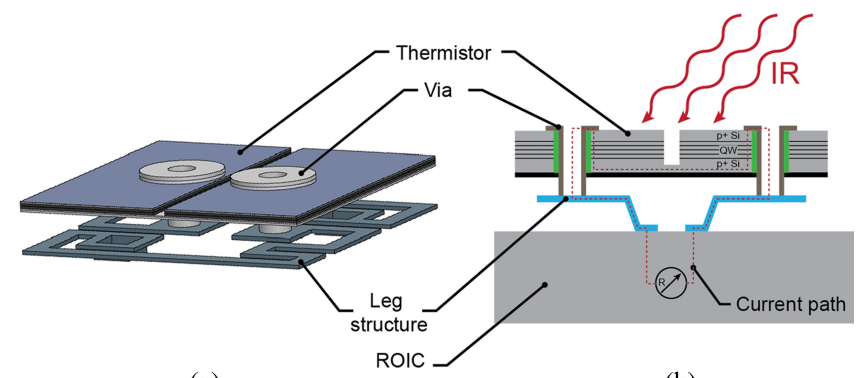

(a)

(b)

Fig. 7. (a) Rendered 3-D image of the umbrella-type microbolometer pixel design, including the microbolometer legs placed underneath the microbolometer membrane. (b) Schematic cross-section of the umbrella-type microbolometer pixel with current path through the $\mathrm{Si} / \mathrm{SiGe}$ quantum-well thermistor. The trench separates the highly doped $\mathrm{Si}$ between the upper contacts.

with oxygen plasma etching as depicted in Fig. 5(i). The last process step consists of a second forming gas anneal in $\mathrm{Ar} / \mathrm{H}_{2}$ for $30 \mathrm{~min}$ at $300^{\circ} \mathrm{C}$ to decrease the contact resistances between the $\mathrm{Si} / \mathrm{SiGe}$ quantum-well thermistor material and the metal microbolometer legs. Fig. 6 shows SEM images with details of the free-etched single layer microbolometer pixels on the CMOSbased read-out integrated circuit wafer. The extracted performance parameters from evaluation pixels of the single-layer microbolometer design are an effective TCR of $-2.6 \% / \mathrm{K}$ with a total microbolometer resistance of $\sim 22 \mathrm{k} \Omega$ at $25^{\circ} \mathrm{C}$. The thermal conductance and the heat capacity of the microbolometer inside a vacuum atmosphere were designed to be $1.4 \times 10^{-7} \mathrm{~W} / \mathrm{K}$ and $6.3 \times 10^{-10} \mathrm{~J} / \mathrm{K}$, respectively. This corresponds to an estimated thermal time constant of $4.6 \mathrm{~ms}$. A process error during the Ni electroless plating caused that a large number of vias were in-completely filled with $\mathrm{Ni}$ as can be seen in Fig. 6(b). Thus, only a few microbolometer pixels were electrically connected to the underlying integrated circuits and although the microbolometer membranes were suspended properly, only very few microbolometer pixels of the evaluated arrays provided an electrical signal from the read-out integrated circuit. Therefore, the wafer-level vacuum packaging and evaluation described in Sections II-C and III. focuses on focal plane arrays with the umbrella-type microbolometers described in Section II-B2.

2) Umbrella-Type Microbolometer Design: Fig. 7(a) and (b) show a rendered 3-D image and a cross-sectional image of the umbrella-type microbolometer design, respectively. In this design, the microbolometer legs are placed underneath the microbolometer membrane. Thus, a very high pixel fill factor for absorbing the incoming infrared radiation can be achieved. The long and narrow microbolometer legs provide a low thermal conductance between the microbolometer thermistor membrane and the read-out integrated circuit substrate. The microbolometer legs consist of a low-stress amorphous TiAl layer that connects the read-out integrated circuit with the uppermost highly doped $\mathrm{Si}$ contact layer of the $\mathrm{Si} / \mathrm{SiGe}$ thermistor. Similar to the singlelayer microbolometer design, the thermistor layer is divided in two halves by an etched trench as indicated in Fig. 7(b). This results in an electrical double pass through the thermistor, so that the two electrical contacts can be realized on the same side of the thermistor. The measurement current from the read-out integrated circuit is guided vertically through the horizontally arranged $\mathrm{Si} / \mathrm{SiGe}$ quantum well layers of the microbolometer membrane. The infrared light absorption in the microbolometer membrane is optimized by designing it as an optical $\lambda / 4$-cavity where the incoming IR radiation is reflected from the backside metal mirror and absorbed by the microbolometer membrane [43]. The optical cavity consists of a bottom Al mirror, the epitaxially grown $\mathrm{Si} / \mathrm{SiGe}$ quantum-well layers, and a thin layer of $\mathrm{MoSi}_{2}$. The optical design of the $\lambda / 4$-cavity was simulated and optimized to absorb $>80 \%$ of the optical power of the targeted wavelengths from 8 to $14 \mu \mathrm{m}$.

Fig. 8 details key steps in the heterogeneous 3-D integration of the umbrella-type microbolometers on top of the read-out integrated circuit wafer. The surface of the CMOS wafer is prepared by depositing a thin layer of $\mathrm{Al}_{2} \mathrm{O}_{3}$ using atomic layer deposition (ALD). The $\mathrm{Al}_{2} \mathrm{O}_{3}$ protects the top dielectric layer of the CMOS wafer during the final release etch of the microbolometers. A layer of $\mathrm{PECVD} \mathrm{SiO}_{2}$ is deposited and contact holes are etched in the $\mathrm{SiO}_{2}$ and $\mathrm{Al}_{2} \mathrm{O}_{3}$ layers to expose the underlying metal contact pads on the CMOS wafer. This is followed by depositing and patterning a TiAl layer that defines the microbolometer legs as depicted in Fig. 8(a). Another layer of PECVD $\mathrm{SiO}_{2}$ is deposited and the surface is planarized using chemical mechanical polishing (CMP) as shown in Fig. 8(b). The thermistor on the thermistor material handle wafer is covered with a layer of $\mathrm{Al}$ $(1 \% \mathrm{Si})$ that defines the backside mirror of the microbolometer membrane. A PECVD $\mathrm{SiO}_{2}$ layer is deposited on top of the $\mathrm{Al}$ layer and thereafter, the wafer surface is planarized using CMP. The layer structure on the thermistor material handle wafer is shown in Fig. 8(c). In a next step, the thermistor material handle wafer and the CMOS wafer are bonded to each other using $\mathrm{SiO}_{2}$-to- $\mathrm{SiO}_{2}$ wafer bonding as shown in Fig. 8(d) [22], [24]. Wafer-to-wafer alignment is not required for the wafer bonding step. The $\mathrm{Si}$ device layer and the $\mathrm{SiO}_{2}$ layer (BOX) of the SOI-based thermistor material handle wafer are removed by a combination of wafer back-side grinding, dry and wet etching. Thus, the thin $\mathrm{Si} / \mathrm{SiGe}$ quantum-well thermistor layer is transferred to the CMOS wafer with intermediate sacrificial $\mathrm{SiO}_{2}$ layers. Next, a thin layer of $\mathrm{MoSi}_{2}$ that acts as an absorber layer is sputter-deposited. This is followed by the deposition of a layer of PECVD $\mathrm{SiO}_{2}$ as indicated in Fig. 8(e). Holes are etched through the stack of $\mathrm{MoSi}_{2}$ and the protective $\mathrm{SiO}_{2}$ to expose the top Si layer of the thermistor. The upper $\mathrm{Al}(1 \% \mathrm{Si})$ metal contacts are formed as indicated in Fig. 8(f). Thereafter, 


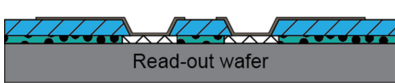

(a)

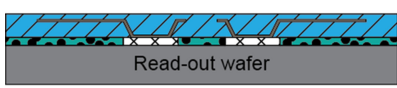

(b)

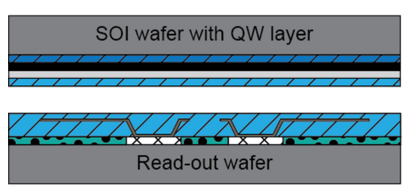

(c)

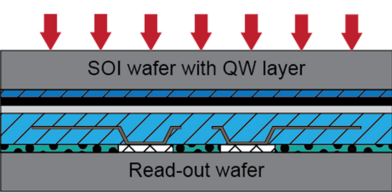

(d)

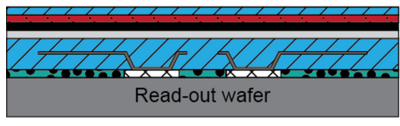

(e)

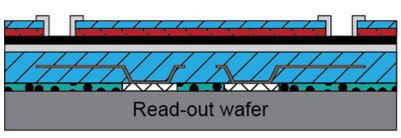

(f)

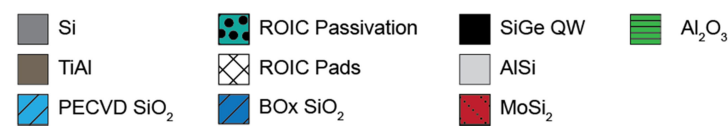

Fig. 8. Schematic process for heterogeneous 3-D integration of the umbrellatype microbolometer design on top of a pre-fabricated CMOS-based read-out integrated circuit wafer.

a trench is etched in the thermistor layer to divide the pixel into two different sections as shown in Fig. 8(g). The microbolometer membranes are defined by etching through the $\mathrm{SiO}_{2}, \mathrm{MoSi}_{2}$, the $\mathrm{Si} / \mathrm{SiGe}$ quantum-well thermistor and the backside $\mathrm{Al}$ mirror, as depicted in Fig. 8(h).

The electrical connections between the TiAl legs and the top layer of the microbolometer thermistor membrane are made with metal plugs that connect to the legs underneath the thermistor, through a hole in the membrane and to the metal contacts on top of the thermistor membrane. The metal plug formation starts by etching holes through the thermistor material, the $\mathrm{Al}$ mirror and the $\mathrm{SiO}_{2}$ down to the TiAl leg metal as shown in Fig. 8(i). Sidewall passivation of the thermistor layers, including inside the etched holes, is done by depositing $40 \mathrm{~nm}$ of $\mathrm{Al}_{2} \mathrm{O}_{3}$ using ALD. The unwanted $\mathrm{Al}_{2} \mathrm{O}_{3}$ layer on the top surfaces is removed by a sputter etch. The sidewall passivation is done to prevent short circuiting of the thermistor layers inside the via-holes and to improve the $1 / \mathrm{f}$ noise properties of the thermistor layer by passivating the sidewall surfaces of the thermistor membrane [22]. TiAl is deposited and patterned to electrically contact the TiAl microbolometer legs with the contact areas of the upper thermistor layer as depicted in Fig. 8(k). The microbolometers

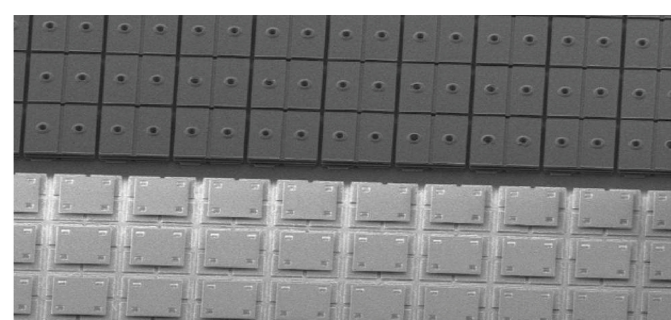

(a)

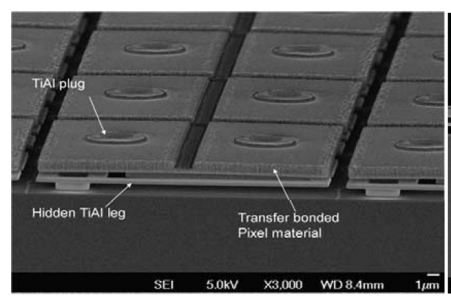

(b)

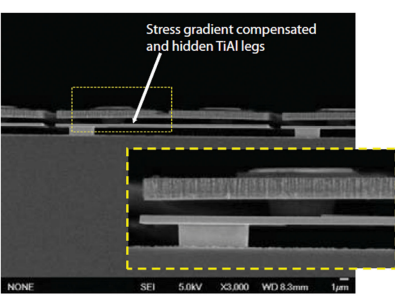

(c)
Fig. 9. SEM images of the umbrella-type microbolometer design. (a) Edge of a microbolometer array with three rows of "blinded" reference pixels. (b) Details of a microbolometer pixel. (c) Cross-section of a free-standing microbolometer with the legs placed underneath the thermistor membrane.

are released using isotropic anhydrous vapor $\mathrm{HF}$ etching of the exposed PECVD $\mathrm{SiO}_{2}$ (not indicated in Fig. 8) after preparing the sealing ring structures on the CMOS wafer for the waferlevel vacuum packaging process as described in Section II-C. The resulting vacuum packaged microbolometers have a measured average TCR of $-2.8 \% / \mathrm{K}$ with a total resistance of $\sim 20 \mathrm{k} \Omega$ at $25{ }^{\circ} \mathrm{C}$. The thermal conductance and the heat capacity of the microbolometer inside a vacuum atmosphere were designed to be $8.8 \times 10^{-8} \mathrm{~W} / \mathrm{K}$ and $8.5 \times 10^{-10} \mathrm{~J} / \mathrm{K}$, respectively. This corresponds to an estimated thermal time constant of $9.6 \mathrm{~ms}$. Fig. 9 shows SEM images with details of free-etched umbrella-type microbolometer pixels.

\section{Wafer-Level Vacuum Packaging of the Microbolometer Focal Plane Arrays}

Hermetic vacuum encapsulation of microbolometer focal plane arrays is required to minimize thermal conductance between microbolometer membranes and their surrounding through gas conduction, and thus to increase the microbolometer sensitivity. Typically, heat transfer through the surrounding gas starts to dominate over heat transfer through the microbolometer legs, for gas pressures above approximately $10^{-2}$ mbar. Highquality, wafer-level vacuum packaging is considered a prerequisite for infrared microbolometer focal plane arrays targeted at emerging low-cost and high volume applications [46]. For high manufacturing volumes, wafer-level vacuum packaging can substantially reduce the packaging cost as compared to chip-scale packaging solutions. The cost of a typical wafer-level package represents only a small part of the total cost of the focal plane array. The infrared microbolometer focal plane arrays in this work are wafer-level vacuum packaged using solid-liquid interdiffusion (SLID) bonding of a cap wafer, where an isothermal solidification of $\mathrm{Cu}$ and Sn occurs [13], [38]. Figs. 10 and 11 show schematics of the wafer-level vacuum packaging process. 

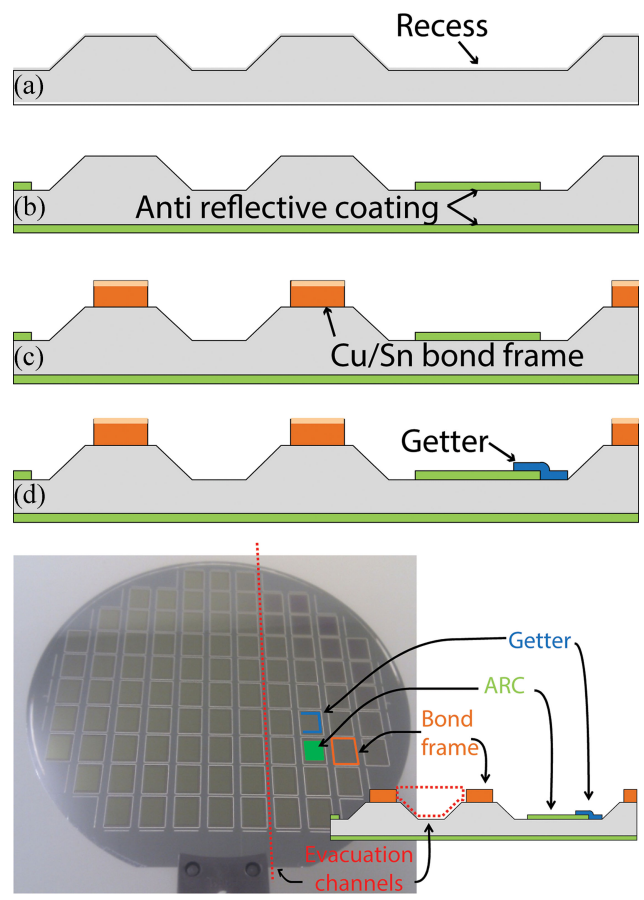

Fig. 10. Process scheme for fabrication of the infrared-transparent cap wafer and photo of the fabricated cap wafer with $\mathrm{Cu}-\mathrm{Sn}$ bond frames.
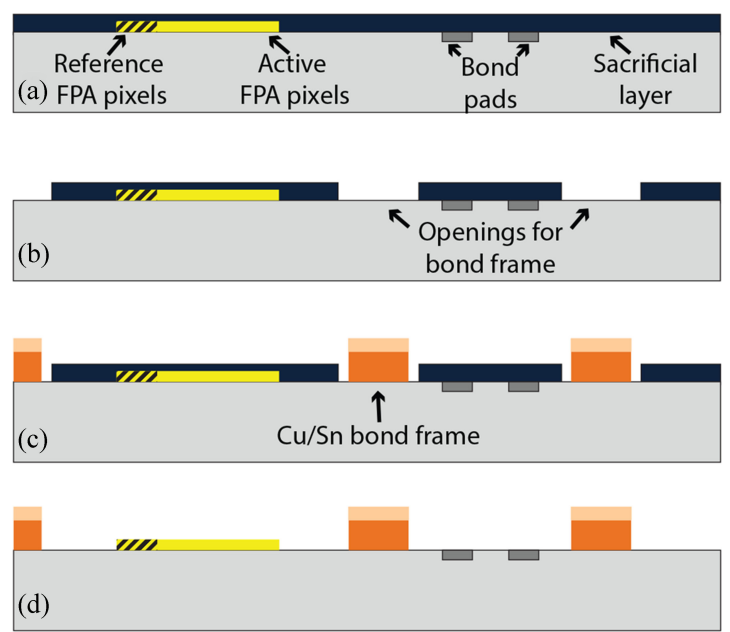

Fig. 11. Preparation of CMOS wafer containing the integrated microbolometer arrays. (a) CMOS wafer with integrated microbolometers, (b) Etching of openings in sacrificial $\mathrm{SiO}_{2}$ layer. (c) Seed layer deposition and electro plating of bond frames with subsequent removal of seed layer. (d) Etching of sacrificial $\mathrm{SiO}_{2}$ layer to release the microbolometers.

Fig. 10 details the preparation of the cap wafer. The Si cap wafer consists of etched recesses that define vacuum cavities and dicing lines as shown in Fig. 10(a).

An antireflective coating is deposited on the top cap surface and at the inside of the cavities to increase the transmission for infrared radiation with the targeted wavelengths from 8 to $14 \mu \mathrm{m}$. The bond frames are defined by electroplating $\mathrm{Cu}$ and Sn on the cap wafer as indicated in Fig. 10(c). A commercially available thin-film non-evaporable getter is sputtered and patterned on the inside of the cavity to improve the vacuum level and long-term reliability of the package. After activation at elevated temperature, the getter acts as a chemical pump that absorbs active gases, including $\mathrm{H}_{2} \mathrm{O}, \mathrm{CO}, \mathrm{CO}_{2}, \mathrm{O}_{2}, \mathrm{~N}_{2}$ and $\mathrm{H}_{2}$. The getter material is not transparent to infrared radiation and the getter structures are therefore located adjacent to the active microbolometer array as depicted in Fig. 10(d). The photo in Fig. 10 shows the finalized cap wafer. The preparation of the CMOS wafer with the integrated microbolometer arrays and the subsequent wafer-level vacuum sealing process is shown in Fig. 11. After patterning the $\mathrm{SiO}_{2}$ layer on the CMOS wafer using wet-etching as shown in Fig. 11(b), sealing ring structures are defined by electroplating $\mathrm{Cu}$ and $\mathrm{Sn}$ as shown in Fig. 11(c). The bond frames on the CMOS wafer correspond to the frames on the cap wafer. At this stage the microbolometers are released by etching the $\mathrm{SiO}_{2}$ using isotropic anhydrous $\mathrm{HF}$ as indicated in Fig. 11(d), resulting in the free-standing microbolometers shown in Fig. 9. All exposed materials, including the $\mathrm{Al}_{2} \mathrm{O}_{3}$ passivation layer and the TiAl microbolometer legs, are not attacked by the anhydrous HF etch. Next, the cap wafer is aligned and joined to the CMOS wafer inside a high vacuum atmosphere. During the $\mathrm{Cu}-\mathrm{Sn}$ bonding process, the wafers are pre-aligned, heated to a temperature below the melting point of $\mathrm{Sn}\left(\mathrm{T}_{\mathrm{m}}=232{ }^{\circ} \mathrm{C}\right)$, and pressed together to ensure good contact between bonding surfaces, while the temperature is ramped up past the Sn melting point [13], [38]. The temperature ramping continues until the targeted bonding temperature (below $300{ }^{\circ} \mathrm{C}$ ) is reached. The temperature ramp is controlled to avoid unwanted flow-out of unreacted Sn, which can cause electrical and mechanical damage to the circuits on the wafer [39]. During bonding, the $\mathrm{Cu}$ and $\mathrm{Sn}$ react and first form a $\mathrm{Cu}_{6} \mathrm{Sn}_{5}$ phase, and subsequently $\mathrm{a} \mathrm{Cu}_{3} \mathrm{Sn}$ phase. The complete transformation of $\mathrm{Cu}$ and $\mathrm{Sn}$ into the $\mathrm{Cu}_{3} \mathrm{Sn}$ phase at the interface requires that the ratio of $\mathrm{Cu} / \mathrm{Sn}$ is above 1.3 [39]. Re-melting of the bond alloy would occur at $415^{\circ} \mathrm{C}$ for bonds consisting of a mixture of $\mathrm{Cu}_{3} \mathrm{Sn}$ and $\mathrm{Cu}_{6} \mathrm{Sn}_{5}$ phases and at $676{ }^{\circ} \mathrm{C}$ for bonds consisting of pure $\mathrm{Cu}_{3} \mathrm{Sn}$ [13], therefore the bond process is optimized as to ensure that the final bondline only comprises $\mathrm{Cu}$ and $\mathrm{Cu}_{3} \mathrm{Sn}$. The singulation and final packaging of the focal plane array chips is illustrated in Fig 12. The lid wafer is diced above the etched recesses to locally remove the lid wafer from the areas that contain the wire bond pads on the CMOS wafer as shown in Fig. 12(b). The related photo shows the wafer with the partly removed lid wafer. Next, the focal plane array chips are diced as indicated in Fig. 12(c), placed in a standard ceramic package and wire bonded as shown in Fig. 12(d). The extracted thermal time constant of the packaged umbrella-type microbolometers is between 8.8 and $9.3 \mathrm{~ms}$, which is close to the designed target value and proves that the gas pressure in the vacuum package is sufficiently low and in the target range. The microbolometer time constant did not degrade when measurements were repeated after more than one year of storage of the packaged focal plane array.

\section{INFRARED CAMERA SYSTEM VERIFICATION}

To demonstrate the packaged $\mathrm{Si} / \mathrm{SiGe}$ quantum well infrared microbolometer focal plane arrays, an evaluation camera 


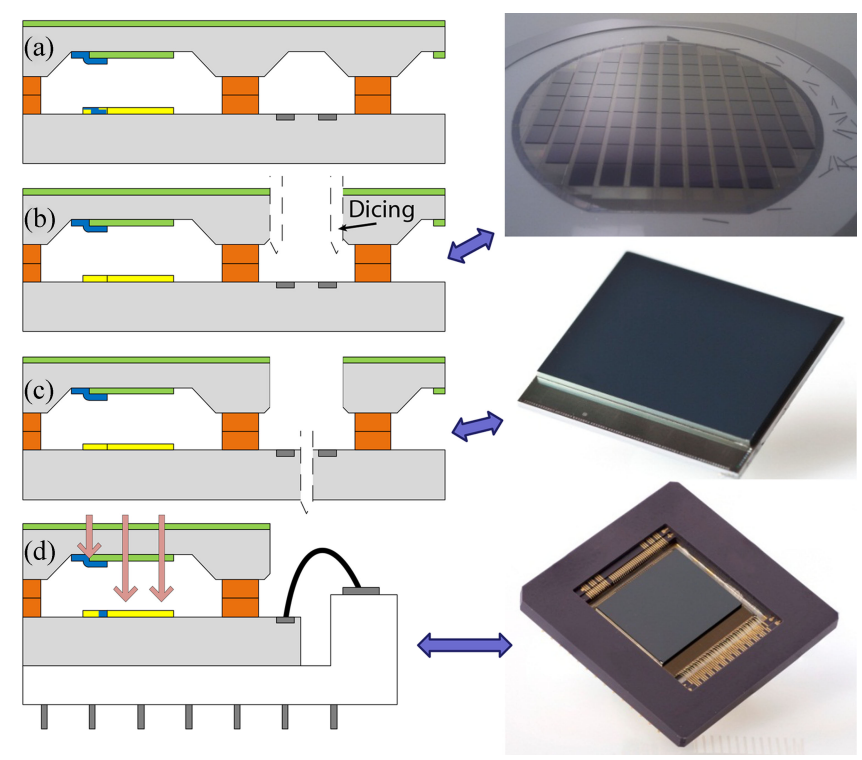

Fig. 12. Singulation process and final packaging of the infrared focal plane array chips.

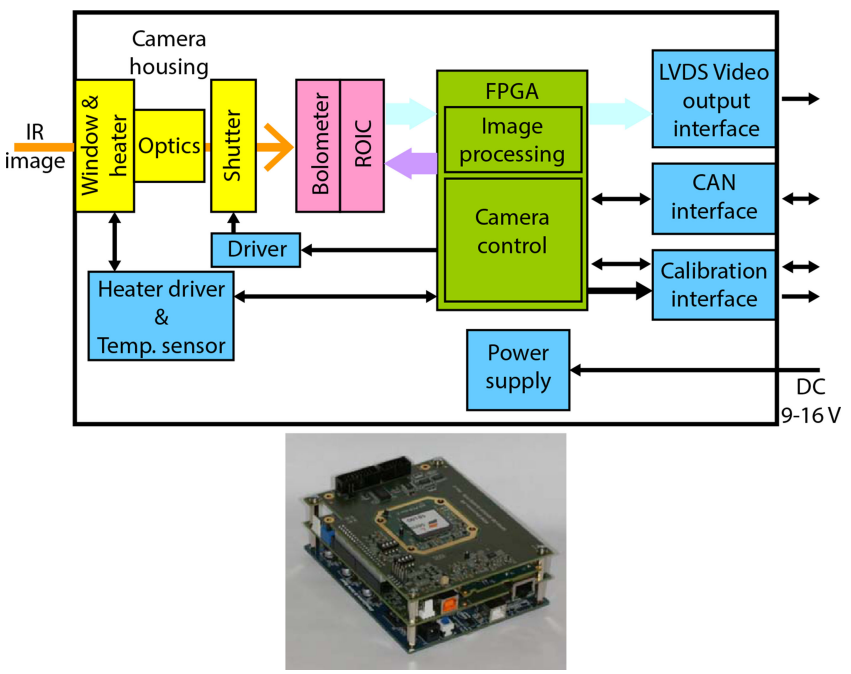

Fig. 13. Block diagram and development board of the IR micobolometer camera.

module was developed and implemented. Fig. 13 shows a schematic block diagram of the camera module and a picture of the assembled camera module that consists of three printed circuit boards and a socket for the ceramic chip package containing the vacuum packaged focal plane array and an infrared lens assembly. The heart of the electronics design in the camera module is an Altera EP3C40 field-programmable gate array (FPGA), used for its high computing power and memory size. The power and heat management, and communication busses are part of the camera module.

Fig. 14 shows a video image frame taken with the $\mathrm{Si} / \mathrm{SiGe}$ quantum-well infrared microbolometer focal plane array. The microbolometer pixel operability of the array is given as the ratio of working pixels compared to the total number of pixels

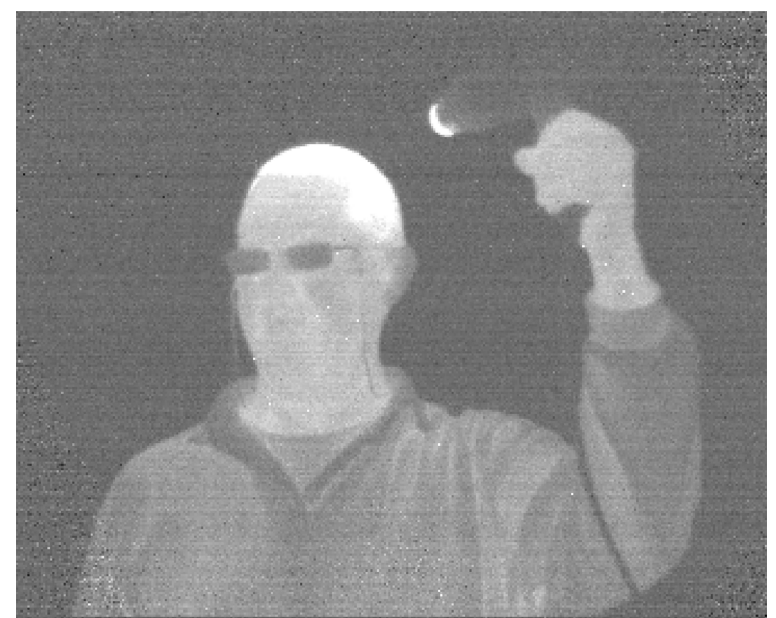

Fig. 14. Video image frame taken with the $\mathrm{Si} / \mathrm{SiGe}$ quantum-well infrared microbolometer focal plane array.

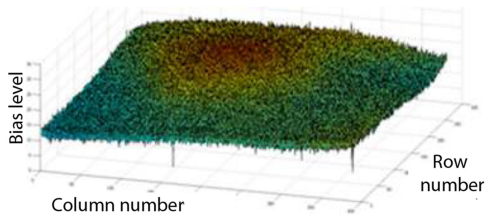

(a)

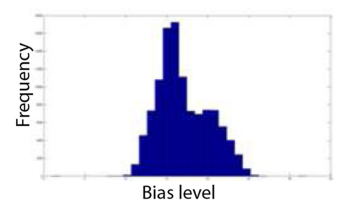

(b)
Fig. 15. (a) Bias level setting for active pixel area with $384 \times 288$ pixels. (b) Histogram of the pixel bias level setting.

of the focal plane array and is targeted to above $99 \%$. This was evaluated by biasing the microbolometer pixels in the focal plane array at different levels and recording the output. Fig. 15 shows the bias level settings for the focal plane array. The average TCR of the focal plane array was evaluated in a controlled temperature environment and was determined to be $-2.8 \% / \mathrm{K}$, which is in line with previous evaluation results from similar microbolometers [22], [23].

\section{CONCLUSION}

This paper reports on operational infrared focal plane arrays utilizing mono-crystalline $\mathrm{Si} / \mathrm{SiGe}$ quantum-well microbolometers that are heterogeneously integrated on top of CMOS-based read-out integrated circuit substrates. The work demonstrates the viability of very large-scale heterogeneous 3-D integration for combining CMOS circuits with advanced infrared microbolometer materials. Heterogeneous 3-D integration enables the independent optimization of the CMOS read-out-integrated circuit electronics and the detector materials and thus, can be employed to implement imaging components with superior performance. Besides for microbolometer focal plane arrays, the demonstrated heterogeneous 3-D integration and packaging approach is a promising technology for a variety of other emerging components, including CMOS-integrated optical sensors, CMOS-integrated photonic and laser systems and CMOSintegrated micro-opto-electromechanical systems (MOEMS). 


\section{REFERENCES}

[1] H. Kaplan, Practical Applications of Infrared Thermal Sensing and Imaging Equipment. Bellingham, WA, USA: The Int. Soc. Opt. Eng., 2007.

[2] M. A. Omar, Y. Zhou, and J. Liu, "Automated applications of the infrared imagers in the automotive assembly lines: Products and process control," Proc. SPIE, vol. 6541, p. 65410E, 2007.

[3] T. Kvisterøy et al., "Far infrared low-cost uncooled bolometer for automotive use," Adv. Microsyst. Autom. Appl., VDI-Buch, pp. 265-278, 2007.

[4] C. Vieider et al., "Low-cost far infrared bolometer camera for automotive use," Proc. SPIE, vol. 6542, pp. 1L.1-1L.10, 2007.

[5] "Flir Unveils the First Personal Thermal imaging Device for Consumers," Flir, Wilsonville, OR, USA, 2014.

[6] H. Budzier and G. Gerlach, Thermal infrared sensors: Theory, Optimisation and Practice. New York, NY, USA: Wiley, 2011.

[7] M.S. Alam and A. Bal, "Improved multiple target tracking via global motion," IEEE Trans. Ind. Electron., vol. 54, no. 1, pp. 522-529, Feb. 2007.

[8] S. A. Merryman and R. M. Nelms, "Diagnostic technique for power systems utilizing infrared thermal imaging," IEEE Trans. Ind. Electron., vol. 42, no. 6, pp. 615-628, Dec. 1995.

[9] P. Kruse, "Can the $300 \mathrm{~K}$ radiating background noise limit be attained by uncooled thermal imagers?," Proc. SPIE, vol. 5406, pp. 437-446, 2004.

[10] D. S. Tezcan, S. Eminoglu, and T. Akin, "A low-cost uncooled infrared microbolometer detector in standard CMOS technology," IEEE Trans. Electron Devices, vol. 50, no. 2, pp. 494-502, Feb. 2003.

[11] P. W. Kruse, Uncooled Thermal Imaging Arrays, Systems, and Applications (SPIE Tutorial Texts in Optical Engineering Vol. TT51). Bellingham, WA, USA: SPIE, 2001.

[12] F. Niklaus, A. Decharat, C. Jansson, and G. Stemme, "Performance model for uncooled infrared bolometer arrays and performance predictions of bolometers operating at atmospheric pressure," Infrared Phys. Technol., vol. 51, no. 3, pp. 168-177, 2008.

[13] A. Lapadatu et al., "Cu-Sn wafer level bonding for vacuum encapsulation of microbolometer focal plane arrays," Trans. ECS, vol. 33, no. 4, pp. 73-82, 2010.

[14] S. H. Black et al., "Advances in high-rate uncooled detector fabrication at Raytheon," Proc. SPIE, vol. 7760, p. 76600X, 2010.

[15] C. Trouilleau et al., "Uncooled amorphous silicon $160 \times 120$ IRFPA with 25 um pixel-pitch for large volume applications," Proc. SPIE, vol. 6542, pp. 1V.1-1V.8, 2007.

[16] U. Mizrahi et al., "Large-format $17 \mu \mathrm{m}$ high-end $\mathrm{VO}_{\mathrm{x}} \mu$-bolometer infrared detector," Proc. SPIE, vol. 8704, p. 87041H, 2013.

[17] M. Kohin and N. Butler, "Performance limits of uncooled VOx microbolometer focal plane arrays," Proc. SPIE, vol. 5406, pp. 447-453, 2004.

[18] D. Murphy et al., "Expanded Applications for high performance $\mathrm{Vo}_{\mathrm{x}}$," Proc. SPIE, vol. 5783, pp. 448-459, 2005.

[19] D. Murphy et al., "High-sensitivity 25- $\mu$ m microbolometer FPAs," Proc. SPIE, vol. 4721, pp. 99-110, 2002.

[20] F. Niklaus, C. Vieider, and H. Jakobsen, "MEMS-based uncooled infrared bolometer arrays: A review," Proc. SPIE, vol. 6836, p. 68360D, 2007.

[21] S. Sedky, A. Witvrouw, H. Bender, and K. Baert, "Experimental determination of the maximum post-process annealing temperature for standard CMOS wafers," IEEE Trans. Electron Devices, vol. 48, no. 2, pp. 377-385, Feb. 2001.

[22] A. Lapadatu et al., "High-performance long wave infrared bolometer fabricated by wafer bonding," Proc. SPIE, vol. 7660, p. 766016, 2010.

[23] F. Forsberg et al., "Very large scale heterogeneous integration (VLSHI) and wafer-level vacuum packaging for infrared bolometer focal plane arrays," Infrared Phys. Technol., vol. 60, pp. 251-259, 2013.

[24] A. Roer, A. Lapadatu, E. Wolla, and G. Kittilsland, "High performance LWIR microbolometer with $\mathrm{Si} / \mathrm{SiGe}$ Quantum well thermistor and wafer level packaging," Proc. SPIE, vol. 8704, p. 87041B, 2013.

[25] F. Zimmer et al., "One-megapixel monocrystalline-silicon micromirror array on CMOS driving electronics manufactured with very large-scale heterogeneous integration," J. Microelectromechanical Syst., vol. 20, no. 3, pp. 564-572, 2011.

[26] M. Lapisa, F. Zimmer, F. Niklaus, A. Gehner, and G. Stemme, "CMOSintegrable piston-type micromirror array for adaptive optics made of mono-crystalline silicon using 3-D integration," in Proc. IEEE Int. Conf. Micro Electro Mech. Syst., 2009, pp. 1007-1010.

[27] M. Lapisa, F. Zimmer, A. Gehner, G. Stemme, and F. Niklaus, "Driftfree micromirror arrays made of monocrystalline silicon for adaptive optics applications," IEEE J. Microelectromechanical Syst., vol. 21, no. 4 , pp. 959-970, Aug. 2012.

[28] M. Lapisa, G. Stemme, and F. Niklaus, "Wafer-level heterogeneous integration for MOEMS, MEMS, and NEMS," IEEE J. Sel. Topics Quantum Electron., vol. 17, no. 3, pp. 629-644, May/Jun. 2011.

[29] M. Esashi and S. Tanaka, "Heterogeneous integration by adhesive bonding," Micro Nano Syst. Lett., vol. 1, no. 3, 2013.

[30] C. M. Liu et al., "MEMS technology development and manufacturing in a CMOS foundry," in Proc. Int. Conf. Solid-State Sens., Actuators, Microsyst., 2011, pp. 807-810.

[31] J. Seeger, M. Lim, and S. Nasiri, "Development of high-performance, high-volume consumer MEMS gyroscopes," InvenSense Inc., Sunnyvale, CA, USA, 2010.

[32] J.-E. Källhammer et al., "Fulfilling the pedestrian protection directive using a long-wavelength infrared camera designed to meet the performance and cost targets," Proc. SPIE, vol. 6198, pp. 74-84, 2006.

[33] F. Niklaus, E. Kälvesten, and G. Stemme, "Wafer-level membrane transfer bonding of polycrystalline silicon bolometers for use in infrared focal plane arrays," J. Micromechanics Microeng., vol. 11, no. 5, pp. 509-513, 2001

[34] F. Niklaus et al., "Characterization of transfer-bonded silicon bolometer arrays," Proc. SPIE, vol. 5406, p. 521, 2004.

[35] F. Forsberg et al., "Heterogeneous 3-D integration of $17 \mu \mathrm{m}$ pitch Si/SiGe quantum well bolometer arrays for infrared imaging systems," J. Micromechanics Microeng., vol. 23, no. 4, p. 045017, 2013.

[36] S. Tohyama et al., "New thermally isolated pixel structure," Proc. SPIE, vol. 5406, pp. 228-236, 2004.

[37] M. Kimata, M. Ueno, M. Takeda, and T. Seto, "SOI diode uncooled infrared focal plane arrays," Proc. SPIE, vol. 6127, p. 61270X, 2006.

[38] N. Hoivik et al., "Fluxless wafer-level Cu-Sn bonding for micro- and nanosystems packaging," in Proc. Electron. Syst.-Integr. Technol. Conf., 2010, pp. 1-5.

[39] T.-T. Luu, A. Duan, K. E. Aasmundtveit, and N. Hoivik, "Optimized $\mathrm{Cu}-\mathrm{Sn}$ wafer-level bonding using intermetallic phase characterization," $J$. Electron. Mater, vol. 42, no. 12, pp. 3582-3592, 2013.

[40] S. Wissmar et al., "High signal-to-noise ratio quantum well bolometer materials," Proc. SPIE, vol. 6401, p. 64010N, 2006.

[41] H. H. Radamson, M. Kolahdouz, S. Shayestehaminzadeh, A. Afshar Farniya, and S. Wissmar, "Carbon-doped single-crystalline SiGe/Si thermistor with high temperature coefficient of resistance and low noise level," Appl. Phys. Lett., vol. 97, no. 22, pp. 223507-1-223507-2, 2010.

[42] J. Y Andersson, P. Ericsson, H. H. Radamson, S. G. E. Wissmar, and M. Kolahdouz, "SiGe/Si quantum structures as a thermistor material for low cost IR microbolometer focal plane arrays," Solid-State Electron., vol. 60, no. 1, pp. 100-104, 2011.

[43] K. C Liddiard, "Application of interferometric enhancement to selfabsorbing thin film thermal IR detectors," Infrared Phys., vol. 34, no. 4, pp. 379-387, 1994.

[44] F. Niklaus, G. Stemme, J.-Q. Lu, and R. J Gutmann, "Adhesive wafer bonding-Applied physics reviews," J. Appl. Phys., vol. 99, no. 1, pp. 031101.1-031101.28, 2006.

[45] F. Niklaus et al., "Wafer bonding with nano-imprint resists as sacrificial adhesive for fabrication of silicon-on-integrated-circuit (SOIC) wafers in 3-D integration of MEMS and ICs," Sens. Actuators A, Phys., vol. 154, no. 1, pp. 180-186, 2009.

[46] M. Esashi, "Wafer level packaging of MEMS," J. Micromechanics Microeng., vol. 18, no. 7, p. 073001, 2008.

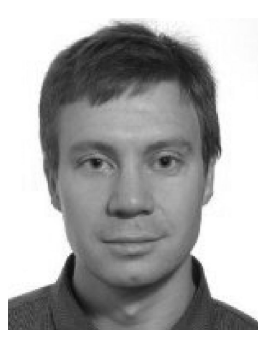

Fredrik Forsberg received the M.Sc. degree in engineering physics from the Chalmers University of Technology, and the Ph.D. degree in microsystem technology from KTH Royal Institute of Technology, Sweden, in 2006 and 2013, respectively. He is currently working as a Researcher at the Department of Micro and Nanosystems, School of Electrical Engineering, KTH Royal Institute of Technology. His research interests include fabrication techniques for 3-D micro- and nanodevices and heterogeneous integration of MEMS and IC technology with a focus on

infrared sensors. 


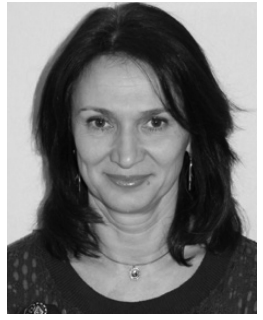

Adriana Lapadatu received the M.Sc. degree from the Faculty of Electronics and Telecommunications, "Politehnica" Institute of Bucharest, Bucuresti, Romania, in 1989, and the M.Sc. and Ph.D. degrees in electrical engineering from the Faculty of Applied Sciences, K. U. Leuven, Belgium, in 1994 and 1999, respectively. She is working at Sensonor, in the R\&D Department. Her present research interests include heterogeneous 3-D integration of MEMS, with emphasis on IR microbolometers and wafer bonding techniques for MEMS.

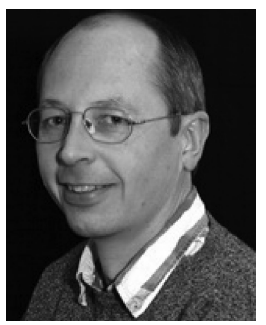

Gjermund Kittilsland received the M.Sc. and Lic.Eng. degrees from the Chalmers University of Technology, Sweden, in 1986 and 1989, respectively. He joined Sensonor AS in Norway in 1992 and has been serving various roles in MEMS development, project management and leadership. Since 2009, he has provided significant contributions to concept and technology development for low-cost microbolometers.

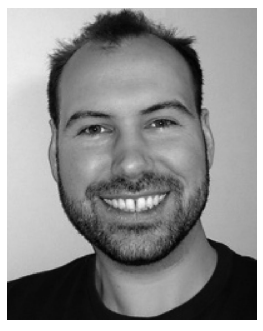

Stian Martinsen received the M.Sc. degree in physics from the Norwegian University of Technology and Science (NTNU), Trondheim, Norway, in 2007. He joined Sensonor AS shortly after, working as a Product Engineer for MEMS tire pressure sensors for two years before joining the R\&D department as a Process Development Engineer. For the last five years, he has been working on developing wafer level test and characterization, thin film deposition and etch, and wafer level bonding (SLID, direct) for new products.

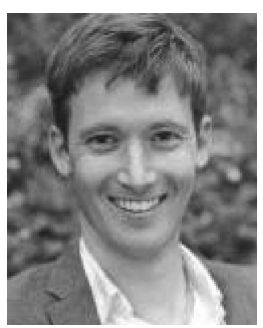

Niclas Roxhed received the M.Sc. degree in electrical engineering in 2003 and $\mathrm{Ph} . \mathrm{D}$. degree in microsystem technology in 2007, both from KTH Royal Institute of Technology, Stockholm, Sweden. He is currently an Associate Professor and a Team Leader of medical MEMS. His main research fields include sensors for medical diagnostics and medical-aid microsystems. He is also involved in high precision etching using DRIE for RF-MEMS switches 3-D integration of MEMS on ICs for infrared imagers. He has authored or coauthored more than 50 scientific papers.

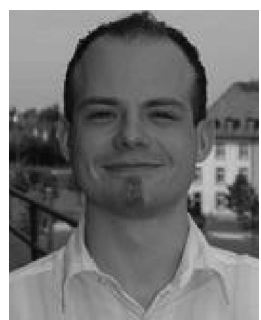

Andreas C. Fischer received the Diploma degree in microsystems engineering from the University of Freiburg, Germany, and the Ph.D. degree in microsystem technology from KTH Royal Institute of Technology, Stockholm, Sweden, in 2008 and 2013, respectively. He is currently working as Researcher at the Department of Micro and Nanosystems, School of Electrical Engineering, KTH Royal Institute of Technology. His research interests include the development of novel integration and fabrication techniques for 3-D micro- and nanodevices, heterogeneous integration of MEMS and IC technology as well as advanced wire bonding technology.

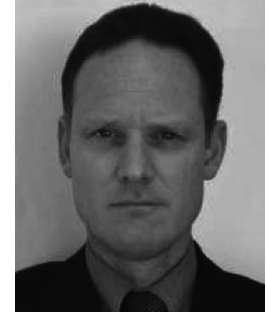

Göran Stemme (F'06) received the M.Sc. degree in electrical engineering in 1981 and the Ph.D. degree in solid-state electronics in 1987, both from the Chalmers University of Technology, Göteborg, Sweden. In 1981, he joined the Department of Solid State Electronics, Chalmers University of Technology. In 1990, he became an Associate Professor (Docent) and the Head of the silicon sensor research group. In 1991, he was the Appointed Professor at KTH Royal Institute of Technology, Stockholm, Sweden, where he is the Head of the Department of Micro and Nanosystems at the School of Electrical Engineering. His research interests include microsystem technology based on micromachining of silicon. The work spans a broad range of technological and application fields such as medical technology, biochemistry, biotechnology, microfluidics, optical applications, waferlevel packaging, and device integration. Some of the results have successfully been commercialized. Between 1995 and 2001, he was a Member of the International Steering Committee of the Conference series IEEE Microelectromechanical Systems and he was the General Cochair of that conference in 1998. He has published more than 260 research journal and conference papers. His publications have more than 3100 citations and an h-index of 28 according to Scopus. He has given invited, keynote, or plenary talks on 20 occasions at international scientific conferences, and he has 23 published patents. He has been a Member of the Editorial Board of the Journal of Microelectromechanical Systems since 1997 and was a Member of the Editorial Board of the Royal Society of Chemistry journal Lab On A Chip between 2000 and 2005. He is a Member of the Royal Swedish Academy of Sciences.

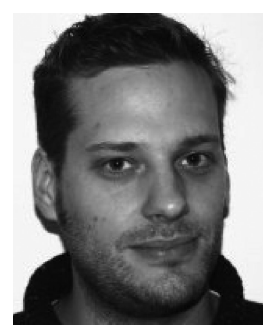

Björn Samel received the Dipl.-Ing. degree in mechatronics (with high Hons.) from the University of Applied Sciences, Ulm, Germany, in 2002 and the $\mathrm{Ph} . \mathrm{D}$. degree in microsystem technology from KTH Royal Institute of Technology, Stockholm, Sweden, in 2007. He worked at $\AA$ AC Microtec from 2007 to 2009 and joined ACREO Swedish ICT in 2009, where he is the Head of the Micro and Nano Fabrication Group.

Per Ericsson received the Ph.D. degree in solid-state electronics from the Chalmers University of Technology, Göteborg, Sweden, in 1997. He worked at Ericsson Microelectronics between 1998 and 2000 with process integration. From 2000 to 2012, he worked at Acreo AB with process development and device design for semiconductor devices and sensors based on $\mathrm{Si}$, SiGe, $\mathrm{SiC}$, and GaN. In 2012, he joined Tobii Technology AB.

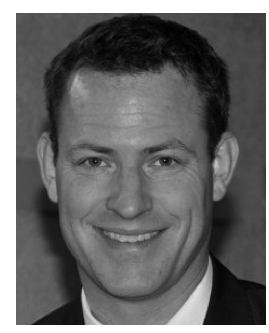

Nils Høivik received the Ph.D. degree in mechanical engineering from the University of Colorado, Boulder, USA, in 2002. In 2003, he joined the IBM T.J. Watson Research Center, Yorktown Heights, NY, where he was the Technical Team Leader for the RF MEMS Group working toward integration of $\mathrm{Cu}-$ based MEMS switches integrated with active $\mathrm{SiGe}$ RF circuits. In 2007, he joined HiVe-Vestfold University College, Department of Micro and Nano Systems Technology. In 2011, he was promoted to the Head of Department. He became Full Professor in 2013, and is also the part of the Management Team for the Ph.D. National Research School in Nanotechnology for microsystems. His research interests include design, fabrication, packaging, modeling, and testing of micro- and nanodevices for RF, optical, energy, and environmental applications. He is currently the Project Leader for a research project related to wafer-level packaging using CuSn SLID bonding. He has authored two book chapters-on RF MEMS and wafer level SLID bonding technology, in addition more than 80 journal and conference articles. He is a Member of IEEE and a Reviewer for the ASME Journal of Electronic Packaging and Micronanoletters. 


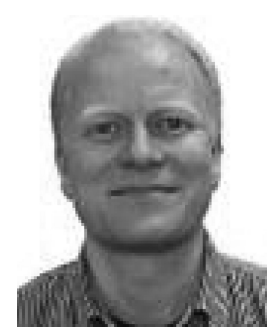

Thor Bakke (M'00) received the Dr.Ing. degrees in electrical engineering from the Norwegian University of Science and Technology, Trondheim, Norway, in 2002. He has conducted research in photonics at Sandia National Laboratories, Albuquerque, NM, USA) and Fraunhofer Institute for Photonic Microsystems-IPMS, Dresden, Germany, and is currently a Senior Scientist in the SINTEF Department of Microsystems and Nanotechnology, Oslo, Norway.

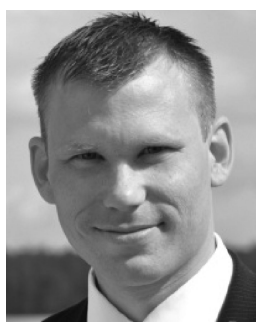

Martin Bring received the M.Sc. degree in materials engineering from the Uppsala University of Technology, Uppsala, Sweden, in 2002 and the Ph.D. degree in electrical engineering from the Chalmers University of Technology, Gothenburg, Sweden, in 2008. He received the Hans Werthén Scholarship from the Royal Swedish Academy of Engineering Sciences in 2008 and a P E Lindahl scholarship from the Royal Swedish Academy of Sciences. He was working at SensorNor from 2010 to 2012 with the development of uncooled microbolometer technology. He is currently R\&D Engineer at Kongsberg Maritime.

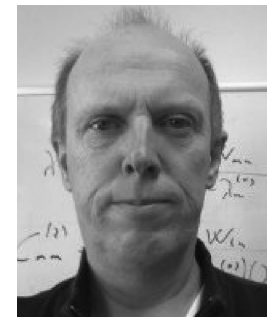

SensoNor.

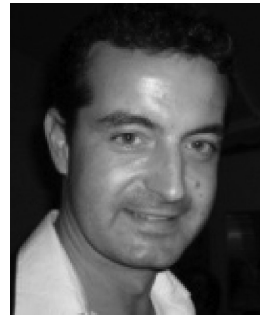

Audun Rør has been with Sensonor since 2001 and he is a Manager of R\&D activities. One of the major products under development at Sensonor is high performance, low-cost microbolometers based on $\mathrm{SiGe}$ quantum well thermistors. He is the Former Program Manager for Tire Pressure Sensor products which is a high-volume MEMS product in the automotive business segment.

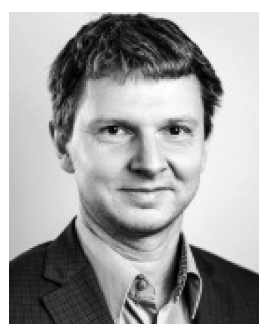

Frank Niklaus (SM'12) received the M.Sc. degree in mechanical engineering from the Technical University of Munich, Munich, Germany, in 1998, and the Ph.D. degree in MEMS from KTH Royal Institute of Technology in Stockholm, Sweden, in 2002. Since 2013 he is a Professor at the Department of Micro and Nanosystems at KTH, where he is leading the Micro and Nanofabrication Group. His research interests include innovative manufacturing, 3D integration and packaging technologies for MEMS and NEMS.
Terje Kvisterøy received the Master's degree in applied physics from the Technical University of Norway, Trondheim, Norway, in 1977. During his military service, he worked as a Researcher in the field of advanced electronic instrumentation at the Norwegian Defense Research Establishment in 1978. He headed the Product Development Department at SensoNor from the start of the company in 1985. From 1992, he held the position of Technical Director. Since 1999, he has been holding the position of Vice-President of Business Development at 